\title{
Hydrothermal synthesis and thermoelectric properties of $\mathrm{PbS}$
}

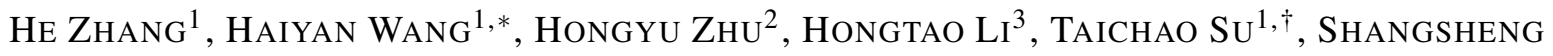 \\ Li $^{1}$, Meihua Hu ${ }^{1}$, HaOtian FAN ${ }^{1}$ \\ ${ }^{1}$ Institute of Materials Science and Engineering, Henan Polytechnic University, Jiaozuo, 454000, China \\ ${ }^{2}$ School of Physics and Chemistry, Henan Polytechnic University, Jiaozuo, 454000, China \\ ${ }^{3}$ Shanghai Entry-Exit Inspection \& Quarantine Bureau, Shanghai, 200135, China
}

\begin{abstract}
In this paper, hydrothermal approach combined with high pressure sintering method was employed to synthesize $\mathrm{PbS}$. The $\mathrm{X}$-ray diffraction results show that single phase $\mathrm{PbS}$ can be obtained by a simple hydrothermal method. The scanning electron microscope results show that the PbS sample has nearly cubic shape and preserves well crystallized and coarse grains after high pressure sintering. The thermoelectric performance of $\mathrm{PbS}$ obtained in this study is comparable to that of a PbS sample prepared by conventional method. The carrier type and concentration of $\mathrm{PbS}$ can be tuned effectively by doping with Bi. The maximum figure of merit for $\mathrm{PbS}$ doped with $1 \mathrm{~mol} \% \mathrm{Bi}$ reaches 0.44 at $550 \mathrm{~K}$, which is about $30 \%$ higher than that of undoped $\mathrm{PbS}$. These results indicate that hydrothermal method provides a viable and controllable way of tuning the electrical transport and thermoelectric properties for $\mathrm{PbS}$.
\end{abstract}

Keywords: PbS; hydrothermal approach; thermoelectric performance; high pressure

(C) Wroclaw University of Technology.

\section{Introduction}

Thermoelectric materials capable of converting energy between heat and electricity are currently attracting significant attention as a part of a search for sustainable alternative energy sources [1-6]. The efficiency of thermoelectric devices is strongly associated with the dimensionless figure of merit ZT defined as:

$$
Z T=\left(S^{2} \sigma / \kappa\right) T
$$

where $\mathrm{T}$ is temperature $[\mathrm{K}], \mathrm{S}$ is Seebeck coefficient, $\sigma$ is electrical conductivity, and $\mathrm{K}$ is total thermal conductivity. Therefore, a combination of a high power factor $\left(S^{2} \sigma\right)$ and low thermal conductivity is an effective way to achieve highperformance thermoelectric materials.

The rocksalt-structured lead-based chalcogenides, have been extensively studied as promising thermoelectric materials [1, 6-9]. Especially lead telluride $(\mathrm{PbTe})$, as one of the most

\footnotetext{
*E-mail: whylxs@126.com

†E-mail: taichao80@hotmail.com
}

frequently investigated materials in this system, remains the top-performing thermoelectric at midtemperature range $(600 \mathrm{~K}$ to $900 \mathrm{~K})$ [10]. However, Te is a scarce element in the crust of the earth $(0.001 \mathrm{ppm}$ by weight). Lead sulfide $(\mathrm{PbS})$ is much less expensive than its analogue PbTe. It is an ideal candidate for widespread application of environmentally stable and affordable thermoelectric material system provided its thermoelectric performance is comparable to that of PbTe. In order to enhance the thermoelectric properties of $\mathrm{PbS}$, a lot of methods have been used, such as heavy doping [11], valence-band offset engineering and introducing nanocrystalline inclusions [8].

Metal sulfides are particularly difficult to synthesize mainly because of volatility of sulfur and its tendency to oxidize. This requires synthesis to be performed in a sealed tube under vacuum conditions. Usually, a conventional method of vacuum melting requires a long-duration heating process. Compared to it, the hydrothermal method is low cost and convenient for operating, what has been used for synthesis of many thermoelectric materials such as $\mathrm{PbTe}[12,13]$, Bi2Te3 [14-16] and 
CoSb3 [17]. As far as we know, there is little reported on the thermoelectric performance of hydrothermal synthesis of $\mathrm{PbS}[18,19]$.

In this paper, both $\mathrm{PbS}$ and $\mathrm{Bi}$ doped $\mathrm{PbS}$ were synthesized by a simple hydrothermal synthesis method and sintered by high pressure method. The temperature dependence of thermoelectric properties of these compounds was studied.

\section{Experimental}

All the chemicals were analytically pure. In a typical synthesis procedure for $\mathrm{PbS}$ and $\mathrm{Bi}$ doped $\mathrm{PbS}\left(\mathrm{Bi}_{\mathrm{x}} \mathrm{Pb}_{1-\mathrm{x}} \mathrm{S}\right), \mathrm{NaOH}(9.6 \mathrm{~g})$ and $\mathrm{NaBH}_{4}(2 \mathrm{~g})$ were dissolved in distilled water $(80 \mathrm{~mL})$ in a $200 \mathrm{~mL}$ Teflon-lined autoclave. $\mathrm{Pb}\left(\mathrm{NO}_{3}\right)_{2}(20 \times$ $(1-\mathrm{x}) \mathrm{mmol})$ were dissolved in distilled water $(80 \mathrm{~mL})$ in a $100 \mathrm{~mL}$ beaker. An ultrasonic cleaning machine was employed to facilitate the dissolution of starting materials introduced before. Sulfur powder $(20 \mathrm{mmol})$ was put into the autoclave; after that, $\mathrm{BiCl}_{3}(20 \times \mathrm{x} \mathrm{mmol})$ was added. Then the solution from the beaker was transferred to the autoclave, and the reaction took place. Finally, the autoclave was sealed and placed in an oven at $453 \mathrm{~K}$ for 12 hours, then cooled naturally to room temperature. The product was filtered and washed with distilled water and ethanol several times, and dried in vacuum at $333 \mathrm{~K}$ overnight. The collected $\mathrm{PbS}$ and Bi doped $\mathrm{PbS}$ powder were shaped and sintered in a cubic anvil high-pressure apparatus (SPD $6 \times 1200$ ) at $1000 \mathrm{~K}$ and $2 \mathrm{GPa}$. The temperature and pressure were maintained for $20 \mathrm{~min}$. After that, the electrical power for the heating was cut off and the pressure was released.

The phase structure of the products was characterized by X-ray diffraction (XRD) using a D8 advanced diffractometer with $\mathrm{CuK} \alpha$ radiation $(\lambda=$ $0.15406 \mathrm{~nm}$ ). The morphology and microstructure studies and energy dispersive X-ray (EDX) analysis of the products were carried out by using a JXA8200 scanning electron microscope (SEM). Hall coefficient was measured using the van der Pauw method with a constant magnetic field of $0.53 \mathrm{~T}$ and the electrical current of $20 \mathrm{~mA}$. The carrier concentration was calculated from the Hall coefficient, assuming a single carrier model as a Hall scattering factor of unity. The Seebeck coefficient and electrical resistivity were measured from $300 \mathrm{~K}$ to $600 \mathrm{~K}$ by LSR-3. The thermal conductivity (K) was calculated by using:

$$
\kappa=D \rho C_{p}
$$

where $\mathrm{D}$ is the thermal diffusivity measured by the laser flash method (Netzsch LFA457), $\rho$ is the density which was measured by Archimedes principle. $\mathrm{C}_{\mathrm{p}}$ is specific heat capacity which was estimated from Dulong-Petit limit.

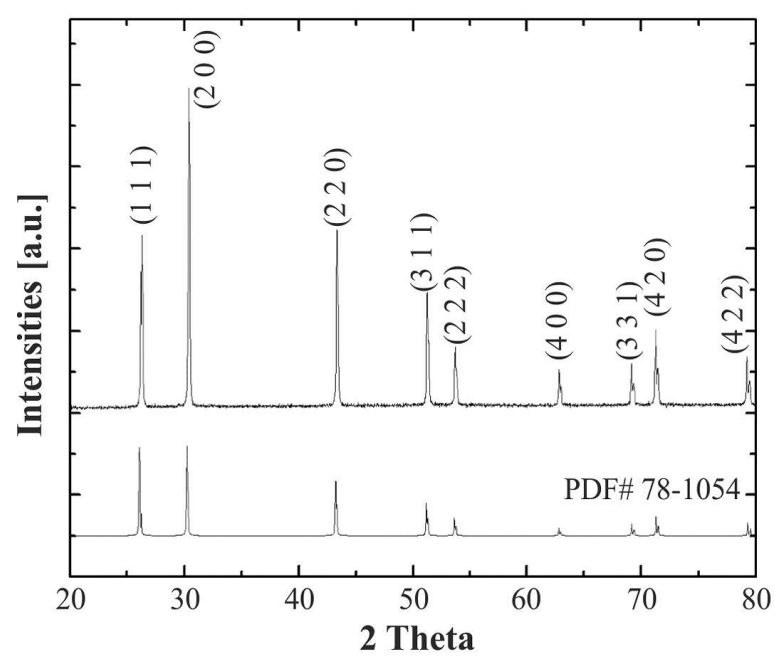

Fig. 1. XRD pattern of hydrothermally synthesized PbS powder.

\section{Results and discussion}

Fig. 1 shows the XRD pattern of hydrothermally synthesized $\mathrm{PbS}$ powder. All the diffraction peaks can be perfectly indexed to $\mathrm{NaCl}$ structure without any noticeable second phase within the detection limit of the XRD equipment. The calculated lattice constant is about $5.913 \AA$ which matches very well with the result of $5.914 \AA$ in the reference (JCPDS Card File: PbS No. 78-1054). The SEM image in Fig. 2 shows that the crystals have a nearly cubic shape which further confirms the presence of cubically structured $\mathrm{PbS}$. The energy dispersive spectrometer (EDS) measurement result shows that the atom fraction of $\mathrm{Pb} / \mathrm{S}$ is about $1: 1.02$ for a hydrothermally synthesized sample. These results indicate that pure phase $\mathrm{PbS}$ was obtained via the simple hydrothermal synthesis method. 
Table 1. Electrical transport properties of $\mathrm{PbS}$ and $\mathrm{Bi}$ doped $\mathrm{PbS}$ samples $\left(\mathrm{Bi}_{\mathrm{x}} \mathrm{Pb}_{1-\mathrm{x}} \mathrm{S}\right)$ at room temperature.

\begin{tabular}{cccccc}
\hline Sample & $\begin{array}{c}\text { Carrier concentration } \\
{\left[10^{18} \mathrm{~cm}^{-3}\right]}\end{array}$ & $\begin{array}{c}\text { Hall mobility } \\
{\left[\mathrm{cm}^{2} / \mathrm{V} \cdot \mathrm{s}\right]}\end{array}$ & $\begin{array}{c}\text { Hall coefficient } \mathrm{R}_{\mathrm{H}} \\
{\left[\mathrm{cm}^{-3}\right]}\end{array}$ & $\begin{array}{c}\text { Resistivity } \\
{\left[10^{-3} \Omega \cdot \mathrm{cm}\right]}\end{array}$ & $\begin{array}{c}\text { Seebeck coefficient } \mathrm{S} \\
{[\mu \mathrm{V} / \mathrm{K}]}\end{array}$ \\
\hline \hline $\mathrm{PbS}$ & 7.36 & 94.12 & 0.85 & 9.02 & 220.44 \\
$\mathrm{Bi}_{0.005} \mathrm{~Pb}_{0.995} \mathrm{~S}$ & 26.31 & 3.313 & -0.24 & 71.61 & -134.29 \\
$\mathrm{Bi}_{0.01} \mathrm{~Pb}_{0.99} \mathrm{~S}$ & 45.215 & 133.99 & -0.14 & 1.03 & -112.27 \\
$\mathrm{Bi}_{0.015} \mathrm{~Pb}_{0.985} \mathrm{~S}$ & 45.387 & 126.83 & -0.14 & 1.08 & -48.48 \\
\hline
\end{tabular}

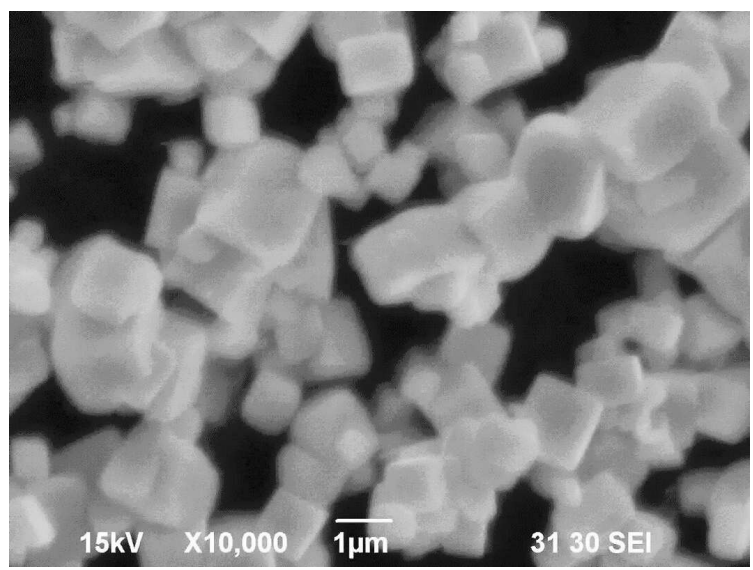

Fig. 2. SEM image of hydrothermally synthesized $\mathrm{PbS}$ powder.

To identify the thermoelectric properties of $\mathrm{PbS}$, high pressure method was employed to sinter the bulk sample. The XRD pattern of high pressure sintered bulk sample is shown in Fig. 3. It can be seen that it is still a single phase PbS. The SEM image of the sample (Fig. 4) shows that it still contains well crystallized and coarse grains, and the void-free structure is consistent with its relatively high density ( 97.7\%). Transgranular fractures and rectangular fractural surfaces are characteristic of the cubic structure of $\mathrm{PbS}$. The measurement results of the electrical transport properties of $\mathrm{PbS}$ are shown in Table 1. It can be seen that the carrier concentration of $\mathrm{PbS}$ is about $7.36 \times 10^{18} \mathrm{~cm}^{-3}$. The value is slightly higher than $1.2 \times 10^{18} \mathrm{~cm}^{-3}$ of the sample prepared by conventional vacuum melting and quenching reported by Pei et al. [20]. It can be attributed to different atom fractions in the samples prepared by different methods. But according to Mahan et al. [21], the carrier concentration is still much lower than in good thermoelectric materials.
In order to tune the carrier concentration of $\mathrm{PbS}, \mathrm{Bi}$ was doped into $\mathrm{PbS}$ as a donor.

The XRD patterns of $\mathrm{PbS}$ doped with $\mathrm{Bi}$ $\left(\mathrm{Bi}_{\mathrm{X}} \mathrm{Pb}_{1-\mathrm{x}} \mathrm{S}, \mathrm{x}=0,0.005,0.01,0.015\right)$ are shown in Fig. 3. It can be seen that all the samples are single phase when the content of additive $\mathrm{Bi}$ is lower than $1.5 \mathrm{~mol} \%$ ( $\mathrm{x}<0.015)$. The impurity phase is found in $\mathrm{Bi}_{\mathrm{x}} \mathrm{Pb}_{1-\mathrm{x}} \mathrm{S}$, when $\mathrm{x}=0.015$. These results indicate that the solubility of $\mathrm{Bi}$ in $\mathrm{PbS}$ is lower than $1.5 \%$.

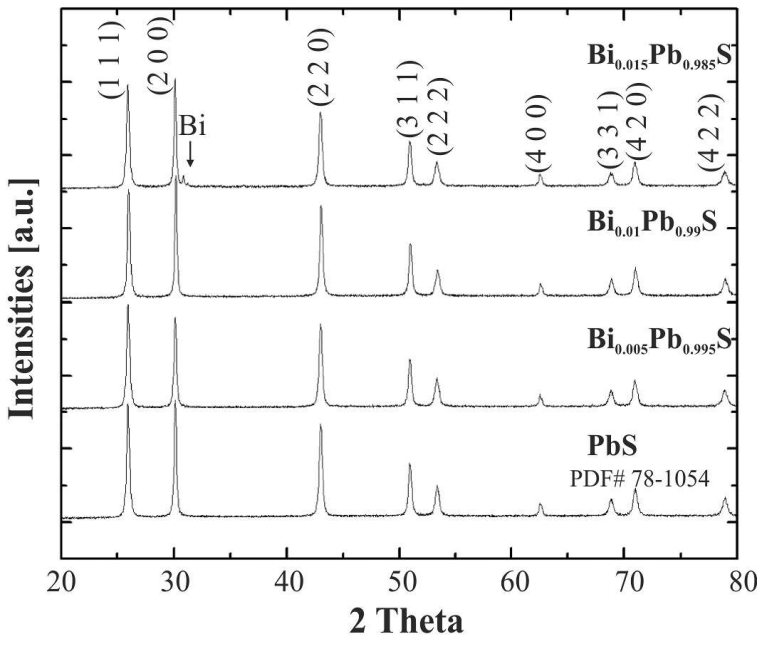

Fig. 3. XRD patterns of high pressure sintered bulk PbS doped with $\mathrm{Bi}$.

Table 1 shows the electrical transport properties of $\mathrm{Bi}$ doped $\mathrm{PbS}$ samples $\left(\mathrm{Bi}_{\mathrm{x}} \mathrm{Pb}_{1-\mathrm{x}} \mathrm{S}\right)$ at room temperature. The value of Hall coefficient changes from positive to negative, which indicates that the conductivity type of $\mathrm{PbS}$ changes from $\mathrm{p}$ to $\mathrm{n}$ after doping with $\mathrm{Bi}$. The carrier concentration of $\mathrm{PbS}$ increases with an increase of $\mathrm{Bi}$ content but the carrier concentration value of $\mathrm{Bi}_{0.015} \mathrm{~Pb}_{0.985} \mathrm{~S}$ is similar to that of $\mathrm{Bi}_{0.01} \mathrm{~Pb}_{0.99} \mathrm{~S}$. These results indicate 


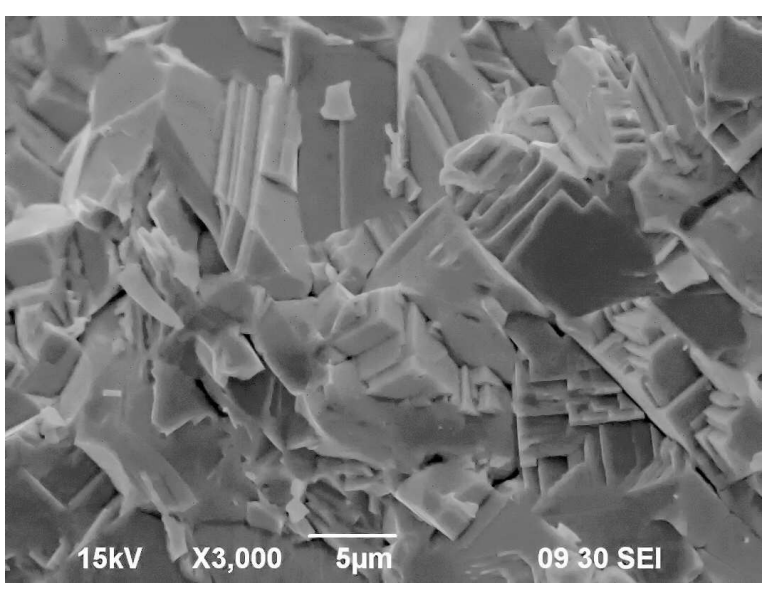

Fig. 4. SEM image of high pressure sintered bulk sample $\mathrm{PbS}$.

that the incorporative rate of $\mathrm{Bi}$ in $\mathrm{PbS}$ is about $1.0 \mathrm{~mol} \%$, which is consistent with the XRD results in Fig. 3. The $\mathrm{Bi}_{0.01} \mathrm{~Pb}_{0.99} \mathrm{~S}$ sample has the lowest resistivity due to its high carrier concentration and large Hall mobility. The Seebeck coefficient changes to negative which is consistent with the Hall coefficient value. The absolute value of Seebeck coefficient decreases with the increase in Bi content. The largest power factor was also obtained for $\mathrm{Bi}_{0.01} \mathrm{~Pb}_{0.99} \mathrm{~S}$ sample.

The temperature dependences of thermoelectric properties including Seebeck coefficient, resistivity and thermal conductivity of $\mathrm{PbS}$ and $\mathrm{Bi}_{0.01} \mathrm{~Pb}_{0.99} \mathrm{~S}$ were measured from $300 \mathrm{~K}$ to $600 \mathrm{~K}$. As seen from Fig. 5, the absolute values of Seebeck coefficient for $\mathrm{PbS}$ and $\mathrm{Bi}_{0.01} \mathrm{~Pb}_{0.99} \mathrm{~S}$ show approximately a linear relationship in the measured temperature range. The slope for $\mathrm{Bi}_{0.01} \mathrm{~Pb}_{0.99} \mathrm{~S}$ is lower than that for $\mathrm{PbS}$. The diffusive part of the Seebeck coefficient (T-linear part) can be described by the formula [22]:

$$
S \propto \pi^{2} \kappa_{B}^{2} T / e E_{F}
$$

where $\mathrm{k}_{\mathrm{B}}, \mathrm{E}_{\mathrm{F}}$, e are the Boltzmann constant, Fermi level and electron charge, respectively. This formula indicates that the slope of the plot $\mathrm{S}$ vs. $\mathrm{T}$ is inversely proportional to the Fermi level. Hence, the reduction of the slope of the plot $\mathrm{S}$ vs. $\mathrm{T}$ for $\mathrm{Bi}$ doped $\mathrm{PbS}$ would reflect the rise of $\mathrm{E}_{\mathrm{F}}$, which is consistent with the increased carrier concentration for $\mathrm{Bi}$ doped $\mathrm{PbS}$.

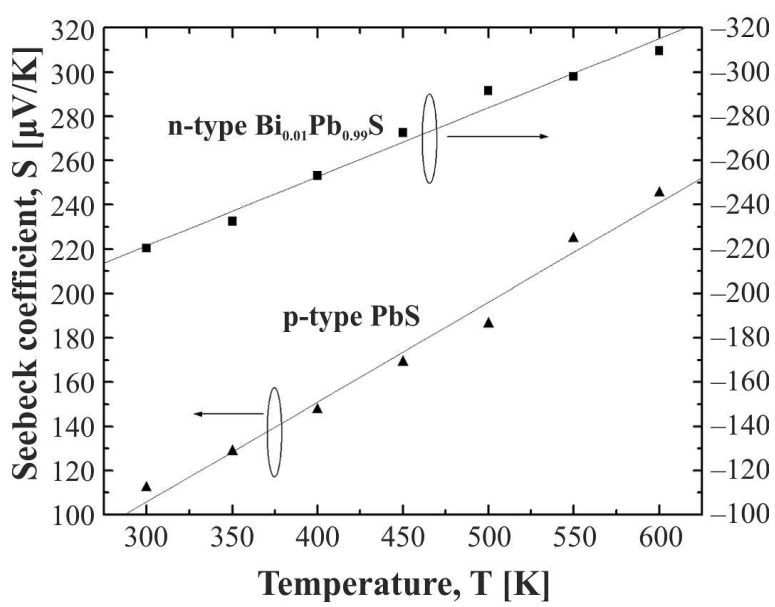

Fig. 5. Temperature dependence of Seebeck coefficient for $\mathrm{PbS}$ and $\mathrm{Bi}_{0.01} \mathrm{~Pb}_{0.99} \mathrm{~S}$.

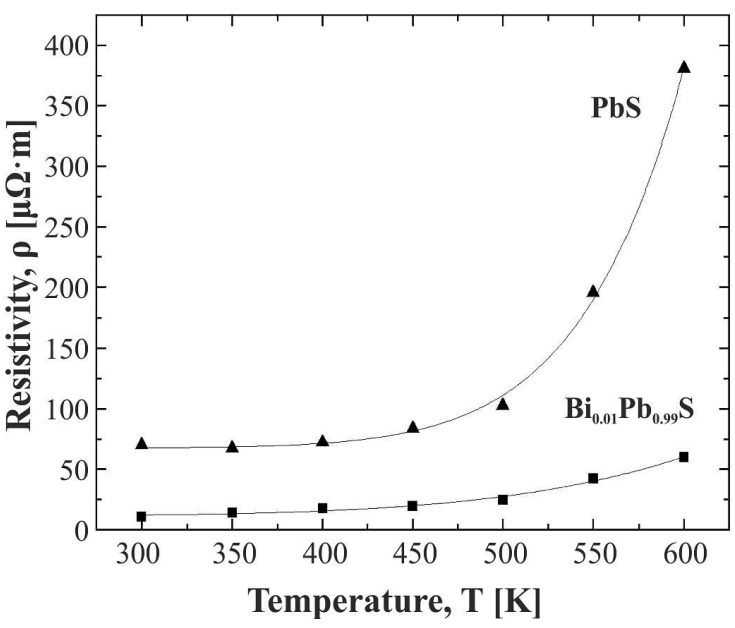

Fig. 6. Temperature dependence of electrical resistivity for $\mathrm{PbS}$ and $\mathrm{Bi}_{0.01} \mathrm{~Pb}_{0.99} \mathrm{~S}$.

Fig. 6 shows the temperature dependence of electrical resistivity for $\mathrm{PbS}$ and $\mathrm{Bi}_{0.01} \mathrm{~Pb}_{0.99} \mathrm{~S}$. The electrical resistivity for both samples increases with the increase of temperature, which is the typical behavior of degenerate semiconductors. The temperature dependence of resistivity can be described well by the power law:

$$
\rho=\rho_{0}+a T^{\gamma}
$$




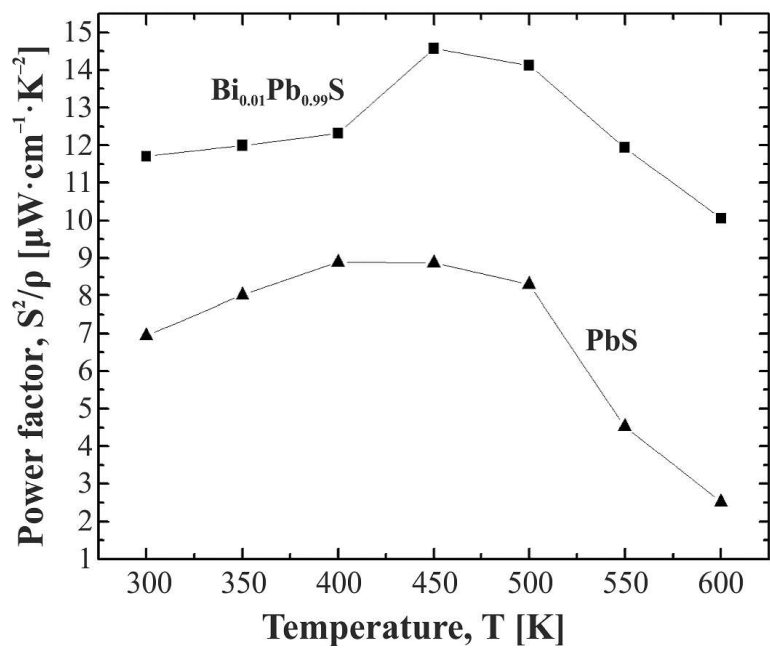

Fig. 7. Temperature dependence of power factor for $\mathrm{PbS}$ and $\mathrm{Bi}_{0.01} \mathrm{~Pb}_{0.99} \mathrm{~S}$.

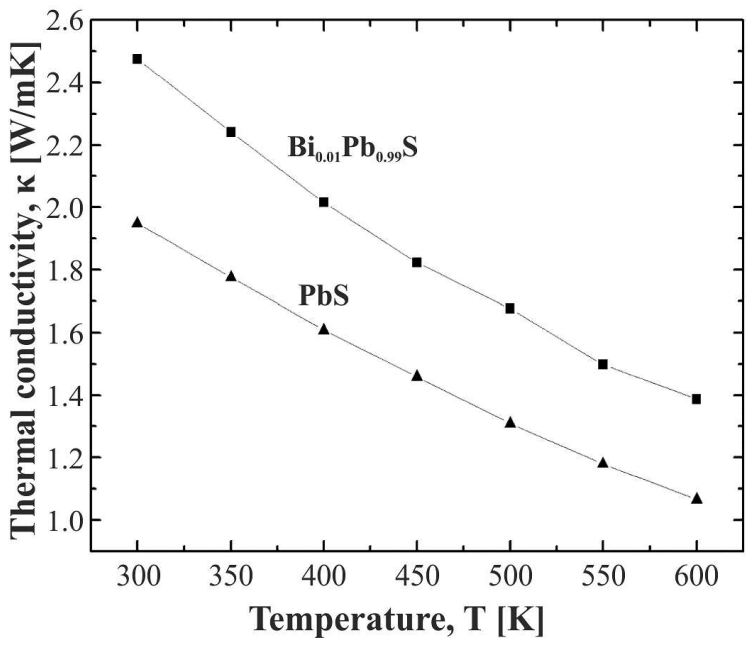

Fig. 8. Temperature dependence of thermal conductivity for $\mathrm{PbS}$ and $\mathrm{Bi}_{0.01} \mathrm{~Pb}_{0.99} \mathrm{~S}$.

The values of $\rho_{0}$ and $\gamma$ obtained from the above formula, are shown in Table 2. The power law dependence of the electrical resistivity results from the phonon scattering of charge carriers [7].

Fig. 7 presents the power factors of $\mathrm{PbS}$ and $\mathrm{Bi}_{0.01} \mathrm{~Pb}_{0.99} \mathrm{~S}$ derived from the electrical conductivities and Seebeck coefficients as a function of temperature. It can be seen that the power factor is higher as $\mathrm{Bi}$ is doped in $\mathrm{PbS}$. The power factors of $\mathrm{PbS}$ and $\mathrm{Bi}_{0.01} \mathrm{~Pb}_{0.99} \mathrm{~S}$ show maximum values of 8.88 and $14.57 \mu \mathrm{W} \cdot \mathrm{cm}^{-1} \cdot \mathrm{K}^{-2}$, respectively.
Table 2. The values of $\rho$, a and $\gamma$ obtained from the formula $\rho=\rho_{0}+\mathrm{aT}^{\gamma}$.

\begin{tabular}{cccc}
\hline Sample & $\rho\left[10^{-6} \Omega \cdot \mathrm{cm}\right]$ & $\mathrm{a}\left(10^{-16}\right)$ & $\gamma$ \\
\hline \hline $\mathrm{PbS}$ & 67.55 & 2.68 & 10.82 \\
$\mathrm{Bi}_{0.01} \mathrm{~Pb}_{0.99} \mathrm{~S}$ & 11.43 & 4.82 & 6.12 \\
\hline
\end{tabular}

Compared to $\mathrm{PbS}$, the maximum power factor peaks of $\mathrm{Bi}_{0.01} \mathrm{~Pb}_{0.99} \mathrm{~S}$ increased by $64.07 \%$.

Fig. 8 shows the temperature dependence of thermal conductivities for $\mathrm{PbS}$ and $\mathrm{Bi}_{0.01} \mathrm{~Pb}_{0.99} \mathrm{~S}$. Generally, the total thermal conductivity has two components, the lattice part $\kappa_{\mathrm{ph}}$ and the electronic part $\kappa_{\mathrm{e}} . \kappa_{\mathrm{e}}$ can be simply estimated through the Wiedemann-Franz law:

$$
\kappa_{e}=L \sigma T
$$

where $\mathrm{L}$ is the Lorenz number. The Lorenz number is estimated by the equation:

$$
L=1.5+\exp [-|S| / 116]
$$

which was proposed by Snyder et al. [12]. The total thermal conductivity of $\mathrm{Bi}_{0.01} \mathrm{~Pb}_{0.99} \mathrm{~S}$ is higher than that of $\mathrm{PbS}$ in the measured temperature range due to its high $\kappa_{\mathrm{e}}$. The $\kappa_{\text {ph }}$ is nearly the same for both samples considering the measurement errors. The $\kappa_{\mathrm{ph}}$ values of both the samples are about $2.0 \mathrm{~W} \cdot \mathrm{m}^{-1} \cdot \mathrm{K}^{-1}$, which is much smaller than that of $\mathrm{PbS}$ prepared by Pei et al. [20] $\left(\sim 2.5 \mathrm{~W} \cdot \mathrm{m}^{-1} \cdot \mathrm{K}^{-1}\right)$ and Wang et al. [11] by other conventional methods. This difference can be attributed to the grain boundaries and crystal defects resulting from hydrothermal process and high pressure compression.

Using the measured electrical transport properties and thermal conductivity, the figure of merit, ZT was calculated. The temperature dependence of $\mathrm{ZT}$ is presented in Fig. 9. The maximum $\mathrm{ZT}$ value for the $\mathrm{PbS}$ is about 0.32 at $500 \mathrm{~K}$, which is about $40 \%$ higher than that of the sample prepared by vacuum melting reported by Pei et al. [20] at the same temperature. In addition, the hydrothermal synthesis and high pressure sintering used in this work is much faster and the technique is very easy compared to the conventional methods. The ZT values of $\mathrm{Bi}_{0.01} \mathrm{~Pb}_{0.99} \mathrm{~S}$ are higher than that of $\mathrm{PbS}$ 
in the measured temperature range. The maximum ZT for $\mathrm{Bi}_{0.01} \mathrm{~Pb}_{0.99} \mathrm{~S}$ is about 0.44 at $550 \mathrm{~K}$, which is about $30 \%$ higher than that of undoped PbS. Further enhanced $\mathrm{ZT}$ value of $\mathrm{PbS}$ based systems can be expected by depressing its thermal conductivity via introducing nanoinclusions.

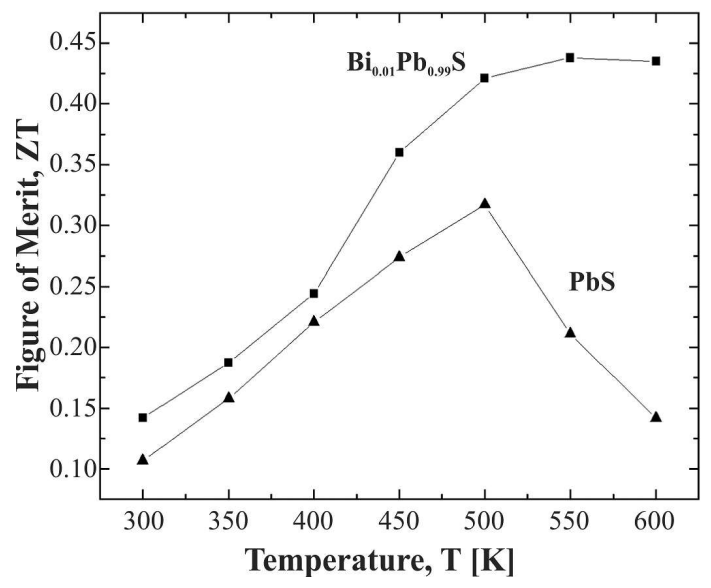

Fig. 9. Temperature dependence of $\mathrm{ZT}$ of $\mathrm{PbS}$ and $\mathrm{Bi}_{0.01} \mathrm{~Pb}_{0.99} \mathrm{~S}$.

\section{Conclusions}

Single phase $\mathrm{PbS}$ was prepared successfully by a simple hydrothermal method. High density bulk samples were obtained by high pressure sintering. The electrical transport and thermoelectric properties of $\mathrm{PbS}$ obtained by hydrothermal and high pressure sintering are comparable to the properties of $\mathrm{PbS}$ compounds prepared by conventional methods. The low level substitution of $\mathrm{Bi}(\leqslant 1.5 \mathrm{~mol} \%)$ for $\mathrm{Pb}$ in $\mathrm{PbS}$ introduces effective electron donors in the lattice and considerably increases the carrier concentration. The maximum figure of merit for $\mathrm{PbS}$ doped with $1 \mathrm{~mol} \% \mathrm{Bi}$ reaches 0.44 at $550 \mathrm{~K}$, which is about $30 \%$ higher than that of undoped $\mathrm{PbS}$.

\section{Acknowledgements}

This work was supported by the Fundamental Research Funds for the Universities of Henan Province
(NSFRF140202), the Foundation for Distinguished Young Scientists of Henan Polytechnic University and the Program of Key Young Teacher of Henan Polytechnic University.

\section{References}

[1] Girard S.N., Schmidt Rohr K., Chasapis T.C., Adv. Funct. Mater., 23 (2013), 747.

[2] Snyder G.J., Toberer E.S., Nat. Mater, 7 (2008), 105 .

[3] Heremans J.P., Jovovic V., Toberer E.S., Science, 321 (2008), 554.

[4] Urban J.J., Talapin D.V., Shevchenko E.V., Nat. Mater, 6 (2007), 115.

[5] Disalvo F.J., Science, 285 (1999), 703.

[6] LeE Y., Lo S.H., Chen C., Nat. Commun., 5 (2014), 4640.

[7] Ravich I.I., Semiconducting Lead Chalcogenides, Springer US, New York, 2013.

[8] Zhao L.D., He J., Hao S., J. Am. Chem. Soc., 134 (2012), 16327.

[9] Wu H., Carrete J., Zhang Z., NPG Asia. Mater, 6 (2014), e108.

[10] LiU W., LuKas K C., Mcenaney K., Energ. Environ. Sci., 6 (2013), 552.

[11] Wang H., Schechtel E., Pei Y., Adv. Energ. Mater., 3 (2013), 488.

[12] Kim H.S., GibBs Z.M., TANG Y., SNyder G.J., APL Mater., 3 (2015), 041506.

[13] Zhu T.J., Chen X., Cao Y Q., J. Phys. Chem. C, 113 (2009), 8085.

[14] Zhao X., Ji X., Zhang Y., Appl. Phys. Lett., 86 (2005), 062111.

[15] CaO Y., Zhao X., ZhU T., Appl. Phys. Lett., 92 (2008), 3106.

[16] Tang X., Xie W, Li H., Appl. Phys. Lett., 90 (2007), 12102.

[17] Alboni P., Ji X., He J., J. Appl. Phys., 103 (2008), 113707.

[18] Johnsen S., He J., Androulakis J., J. Am. Chem. Soc., 133 (2011), 3460.

[19] Kuang D., Xu A., FAng Y., Adv. Mater., 15 (2003), 1747.

[20] Pei Y.L., LiU Y., J. Alloy. Compd., 514 (2012), 40.

[21] Mahan G., Solid State Phys., 51 (1997), 81.

[22] Li D., Yang K., Hng H., J. Appl. Phys., 104(2008), 103720. 